\title{
Quality Assessment of Technical Education using SERVQUAL: S/N Ratio and Grey Relation Analysis
}

\author{
Amol Nayakappa Patil*, V. Mariappan, Leslie C. D'souza, and Reuben J. Nazareth \\ Department of Mechanical Engineering, Agnel Institute of Technology and Design, Assagao, Bardez-Goa, 403507, India
}

\begin{abstract}
Education has a considerable role in the development of our future. Hence, the quality of education is of prime importance in crafting the future of our country. Services offered by education institutes articulate the quality of the education. This is also valid to higher education. Higher education institutes in India are increasing and thus, to remain competitive, they strive to improve the quality of education. Technical institutes are growing at a rapid pace compared to non-technical and the same is experienced in the Goa state. Hence, this paper focuses on technical higher education in Goa, India. This research investigates service attributes contributing towards the quality of technical education and suggests operating levels of these attributes to improve student performance in academics. To distinguish quality of technical education, a face to face survey with stakeholders was conducted. The SERVQUAL form questionnaire addresses five service quality dimensions. Further analysis was carried out using Signal to Noise ratio and Grey Relation Analysis to predict optimal levels of service attributes to improvised student performance.
\end{abstract}

Keywords: higher education; service quality; SERVQUAL; Signal to Noise ratio; Grey relation analysis; Taguchi's approach

(Submitted on August 6, 2019; Revised on November 11, 2019; Accepted on November 24, 2019)

(C) 2019 Totem Publisher, Inc. All rights reserved.

\section{Introduction}

Education has a significant role in achieving economic growth and development. In addition, it plays an important role in an individual's life as it helps shape their future, which in turn shapes the future of society [1]. This makes quality education a crucial factor for all the stakeholders involved. For higher education, India is third largest in terms of students. India's higher education sector is growing in number of universities and colleges [2]. This is not uncommon in technical education. The quality of the education provided by technical institutes of any country determines its global position. Innovative practices are needed to improve the quality of education. To initiate innovative practices in education, it is important to take perceptions and expectations of stakeholders into consideration and improve upon where expectations are higher than perceptions. This article focuses on the needs and requirements of technical students in Goa, India. The SERVQUAL multi dimension instrument gathers student perceptions and expectations in regards to technical education across three colleges in Goa, India. Based on findings of SERVQUAL, Taguchi's S/N ratio analysis is used to find optimal levels of parameters to maximize marks scored by students. Results attained using the $\mathrm{S} / \mathrm{N}$ ratio is compared with the grey relation analysis as verification and a conclusion is made.

This paper is organized as follows: Section II describes SERVQUAL, the Taguchi approach and Grey Relation analysis. Section III briefs about methodology used. Section IV reports the findings of the survey, deals with data collection and determines satisfaction level. Section V identifies optimal levels to maximize student marks and predicts scores for defined optimal levels. Section VI illustrates study conducted.

\section{Literature Review}

Education is a service industry; it serves as a benchmark quality of services offered by institutes. Service quality can be

\footnotetext{
* Corresponding author.

E-mail address: a17_patil@yahoo.com
} 
studied using various models. The most popular model is SERVQUAL, which separates quality of service into five dimensions known as RATER. The review focuses on the SERVQUAL approach, along with the Taguchi's method and Grey Relation Analysis.

\subsection{SERVQUAL}

In 1988, Zeithaml, Parasuraman and Berry developed SERVQUAL. SERVQUAL was designed with five components, which include Reliability, Assurance, Tangibles, Empathy and Responsiveness. These five components are also acknowledged as dimensions and are universally known as RATER. RATER includes 22 questions. These 22 questions measure customer expectations and perceptions on RATER dimensions. Each dimension includes four or five questions within it [3]. Measure of customer expectations and perceptions calculates service quality by calculating the difference between the two. A smaller difference value indicates customer satisfaction and a larger value shows customer dissatisfaction [4].

\subsection{Taguchi's Method}

The Taguchi method is a statistical approach developed by Genichi Taghuchi with aim to improve the quality of manufactured products. Initially, the approach was used in manufacturing and later expanded to other fields of engineering. Statisticians have acknowledged that the Taghuchi's method is good for studying variation in processes [5]. Variation reduction using Taguchi's approach is based on parameter design and signal to noise ratio application. In parameter design, factors are classified into control and noise factors. Control factors are factors that have control, whereas noise factor do not have control. These parameters are organized using an orthogonal array and the Signal to Noise ratio is calculated. A higher Signal to Noise ratio makes the design more robust [6].

\subsection{Grey Relation Analysis}

The Grey Relation Analysis is a method that is mainly used to compare alternatives with many criteria whose magnitude is expressed in numerical value. The method is based on the grey theory information and is classified as white, black and grey based on nature [7]. When the range of magnitude of criteria with respect to alternative is too large, it will cause weight of criteria to be neglected. Even the direction of criteria may be different, which may lead to wrong results and hence, preprocessing is done on data, which is called grey relation generating. There are three types of processing: higher the better, lower the better, and desired value [8].

\section{Methodology}

The aim of the study is to illustrate critical factors contributing towards the quality of higher education. The stakeholder approach is used to design questionnaires under each dimension of SERVQUAL. The stakeholder approach application is very crucial in higher education quality improvement, as these stakeholders are very important in evaluation, quality assurance and program development [9-10]. A variety of stakeholders involved in the education system are as shown in Figure 1. Exhaustive discussions with all stakeholders facilitated formation of structured questionnaire statements. 27 questionnaire statements with five RATER dimensions were used for research purposes. The SERVQUAL forms were designed to collect inputs from stakeholders who are directly impacted by service quality of higher education.

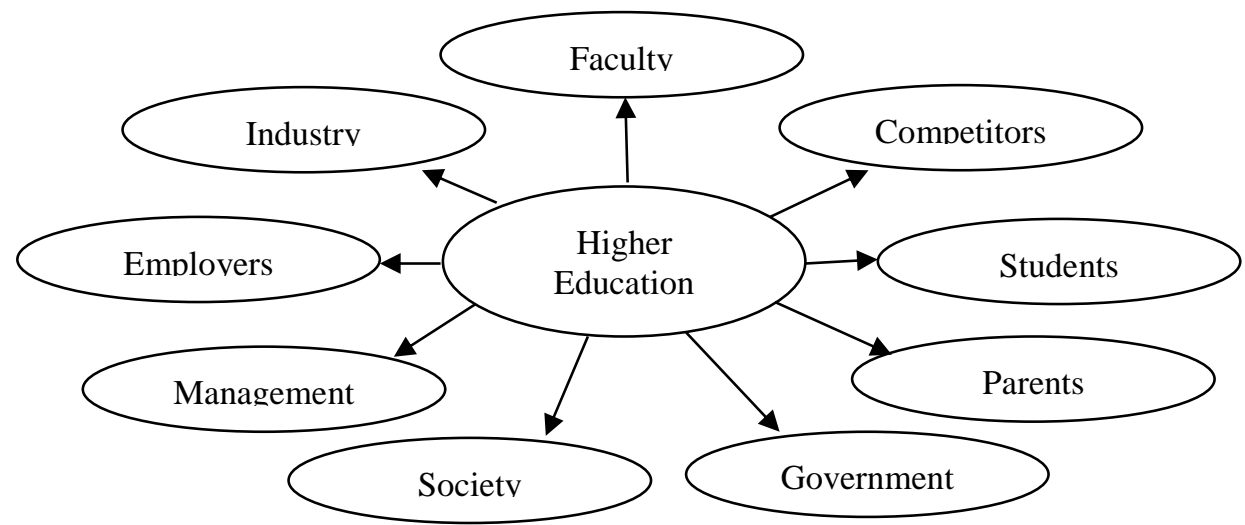

Figure 1. Higher Education Stakeholders 
Though there are a number of stakeholders involved in the education system, the students are considered as primary and key stakeholder of this service. Understanding the needs of students as stakeholders is important in creating and providing a higher education service. Students are interested in quality education, adequate academic environment, employability skills, active participation, etc. During data collection, it was necessary to avoid wrong student input. Wrong student input was avoided by a face to face survey approach. A sample of sixty students was taken from three-year mechanical engineering students across three colleges in Goa. Once the survey was completed, there were 180 interviews that could be used for further analysis.

The SERVQUAL form consisted of two sections; the first section wanted to know which dimension is more important. Dimensions with prime importance will get the highest score, whereas dimensions with the least importance will get the lowest score. The second section of the SERVQUAL form contains questionnaire statements along with expectations and perception measurements with 7 point likert scales. A 1 rating means totally disagree, and a 7 rating means totally agree.

Further analysis of perception and expectation across three colleges was carried out to find the service quality level of each statement. Questionnaire statements that lead to major dissatisfaction across all three colleges was identified, and the first five were considered for Signal to Noise ratio analysis. Based on the service quality gap value, colleges were given two levels: high and low. Later, an L8 orthogonal array with five identified questionnaire statements was designed for experimentation purposes. Marks obtained by five students out of sixty were considered for further analysis. The semester five critical subject machine design score and total score were considered. Optimum levels of each factor was later determined using Taguchi's signal to noise ratio. Optimum levels were confirmed using the grey relation analysis and based on the level prediction of the score.

\section{Findings}

Out of 180 SERVQUAL forms, five forms were discarded as the score of perception and expectation for all questionnaire statements were the same. Hence, this research result is based on findings of 175 SERVQUAL forms. The number of forms considered for analysis is much greater than the optimum sample size required. Internal consistency of data was confirmed by Cronbach's alpha value and was found to be greater than 0.8 .

\subsection{SERVQUAL Dimension Ratings}

Findings related to dimension ratings are as given in Table 1. The students were asked to give weights to SERVQUAL dimensions. A total of 100 points were distributed among RATER as per student's perception. Highest points were assigned to the dimension they perceived to have a larger impact of the quality of higher education and vice versa.

\begin{tabular}{|l|c|c|c|c|}
\multicolumn{7}{l}{ Table 1. RATER dimension rating } \\
\hline Dimensions & College 1 & College 2 & College 3 & Total \\
\hline Reliability & 17.43 & 21.65 & 17.88 & 18.98 \\
\hline Assurance & 16.11 & 18.56 & 17.7 & 17.46 \\
\hline Tangibility & 20.63 & 18.95 & 21.81 & 20.46 \\
\hline Empathy & 20.35 & 17.83 & 20.01 & 19.41 \\
\hline Responsiveness & 25.46 & 23.01 & 22.58 & 23.68 \\
\hline
\end{tabular}

\subsection{Service Quality Gap Score}

The Service Quality Gap score is calculated for each questionnaire statement. Each of the statements is used to measure student's expectation (E) and perception $(\mathrm{P})$ of the service provided by colleges. The difference between perception and expectation gives a Service Quality Gap score. A smaller value of the gap score is indication of poor service quality leading to student dissatisfaction towards the particular service. College 1's student average perception, expectation, gap score and weighted gap score is as shown in Table 2. Weighted gap score is calculated by finding the product of gap scores and dimension weights.

Table 3 shows a summarized weighted gap score for all three colleges. The weighted gap score for all questionnaire statements is negative, which means services need to be looked upon for improvement. Since focusing on all services at one time is very difficult, the five foremost negative gap scores were considered for further analysis. Timely completion of syllabus of college 2 is -74.60 , provision of course material of college 1 is -66.70 and college 2 is -71.84 , monitoring of teaching learning process of college 2 is -66.17 , remedial/coaching classes for weak students of college 2 is -62.19 and 
timely addressing of student difficulties and problems of college 2 is -62.36 . These five statements are considered for signal to noise ratio calculation. Statements are considered as factors and the coding for factors is given in Table 4.

\begin{tabular}{|c|c|c|c|c|c|}
\hline 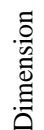 & Question/Statement & $\begin{array}{l}\text { Perception } \\
\text { Score }\end{array}$ & $\begin{array}{c}\text { Expectation } \\
\text { Score }\end{array}$ & $\begin{array}{l}\text { Gap } \\
\text { Score }\end{array}$ & $\begin{array}{l}\text { Weighted } \\
\text { Gap Score }\end{array}$ \\
\hline \multirow{7}{*}{ 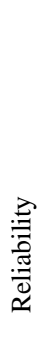 } & Effectiveness of delivery of lectures and practical's & 4.45 & 6.18 & -1.73 & -32.98 \\
\hline & Timely completion of syllabus & 4.67 & 6.37 & -1.7 & -32.28 \\
\hline & Effective utilization of technology and resources & 4.03 & 6.12 & -2.08 & -39.66 \\
\hline & Effectiveness of evaluation method/method of examination & 4.50 & 6.06 & -1.55 & -29.57 \\
\hline & Placement opportunities and career guidance & 3.55 & 6.59 & -3.03 & -57.63 \\
\hline & Provision of course material & 4.14 & 7.65 & -3.51 & -66.70 \\
\hline & Punctuality and sincerity of staff & 5.7 & 6.24 & -0.54 & -10.30 \\
\hline \multirow{5}{*}{ 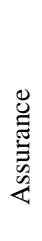 } & Qualified and competent teaching faculty & 4.72 & 6.47 & -1.74 & -30.52 \\
\hline & Monitoring of teaching learning process & 4.34 & 6.17 & -1.82 & -31.94 \\
\hline & Teaching plan and academic calendar & 4.56 & 6.07 & -1.50 & -26.25 \\
\hline & Inspiration of faculty inside and outside the class & 4.25 & 5.99 & -1.73 & -30.36 \\
\hline & Organising/participation in workshops, events, internships, field visits & 4.29 & 6.24 & -1.95 & -34.11 \\
\hline \multirow{5}{*}{ 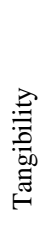 } & Well-equipped and maintained laboratories and classrooms & 4.53 & 6.41 & -1.87 & -38.47 \\
\hline & Library/Learning resources & 4.95 & 6.30 & -1.35 & -27.66 \\
\hline & Transport facilities & 3.47 & 5.98 & -2.51 & -51.50 \\
\hline & On Campus hostel and canteen facilities & 2.84 & 5.51 & -2.67 & -54.70 \\
\hline & Internet facilities and communication methods & 2.77 & 5.01 & -2.23 & -45.67 \\
\hline \multirow{5}{*}{ 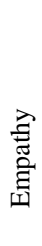 } & Counselling and mentoring process & 4.17 & 5.92 & -1.74 & -33.87 \\
\hline & Remedial/coaching classes for weak students & 4.02 & 5.77 & -1.74 & -33.91 \\
\hline & Willingness of faculty in solving student difficulties & 4.77 & 6.3 & -1.52 & -29.56 \\
\hline & Use of strategies such as teaching students in small batches & 5.05 & 6.09 & -1.03 & -20.04 \\
\hline & Training in aptitude and soft skills to help in placements & 4.11 & 6.34 & -2.23 & -43.29 \\
\hline \multirow{5}{*}{ 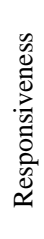 } & Timely addressing of student difficulties and problems & 4.71 & 6.09 & -1.38 & -32.80 \\
\hline & Awareness programs regarding opportunities for higher studies, education & 4.36 & 6.10 & -1.74 & -41.40 \\
\hline & Book bank and scholarship facilities for needy students & 4.31 & 6.00 & -1.69 & -40.04 \\
\hline & Promptness in addressing infrastructure and equipment failure & 3.56 & 6.00 & -2.44 & -57.89 \\
\hline & Effectiveness of Feedback mechanism and grievance redressal system & 4.19 & 6.07 & -1.87 & -44.34 \\
\hline
\end{tabular}

\section{Exploration}

\subsection{Signal to Noise Ratio}

A L8 orthogonal design is used to determine the optimum levels of factors. Two levels of factors are defined based on the weighed gap score. Weighted gap scores of two colleges that are closer to each other is defined at one level, either low or high, and college that is left out has a weighted score that is defined at the other level. Table 5 shows factor coding and factor levels for three colleges. From Table 5, it is evident that college 2 is operating with all factors at a low level and that college 3 is operating with all factors at a high level. For college 1, only factor B is at a low level.

Considering five factors and two levels requires 64 trials. Since the aim was to find optimum levels of factors, a fractional factorial design was used to reduce the number of trials. A L8 orthogonal design is used and the responses for each trial are marked secured by students in the machine design subject and total marks. Now, while selecting students, it 
was very essential that the input quality of students across all colleges is identical. Students selected were diploma students, as input quality of these students across all colleges is similar. The numbers of replicates decided were five, and hence the five top diploma student marks were considered for analysis. A L8 orthogonal array with marks in machine design and total score is shown in Table 6 . The conducting run was not possible, and hence, an approximation was done for each trial.

Table 3. Weighted gap score for college 1, college 2, and college 3

\begin{tabular}{|c|c|c|c|c|}
\hline \multirow{2}{*}{ 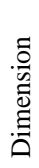 } & \multirow[b]{2}{*}{ Question/Statement } & \multicolumn{3}{|c|}{ Weighted Gap Score } \\
\hline & & College 1 & College 2 & College 3 \\
\hline \multirow{7}{*}{ 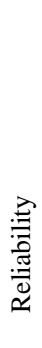 } & Effectiveness of delivery of lectures and practical's & -32.98 & -40.20 & -26.26 \\
\hline & Timely completion of syllabus & -32.28 & -74.60 & -25.63 \\
\hline & Effective utilization of technology and resources & -39.66 & -55.06 & -31.96 \\
\hline & Effectiveness of evaluation method/method of examination & -29.57 & -60.13 & -26.58 \\
\hline & Placement opportunities and career guidance & -57.63 & -44.14 & -47.78 \\
\hline & Provision of course material & -66.70 & -71.84 & -20.25 \\
\hline & Punctuality and sincerity of staff & -10.30 & -27.21 & -16.77 \\
\hline \multirow{5}{*}{ 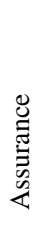 } & Qualified and competent teaching faculty & -30.52 & -43.94 & -18.62 \\
\hline & Monitoring of teaching learning process & -31.94 & -66.17 & -24.44 \\
\hline & Teaching plan and academic calendar & -26.25 & -42.48 & -16.58 \\
\hline & Inspiration of faculty inside and outside the class & -30.36 & -45.10 & -28.81 \\
\hline & Organising/participation in workshops, events, internships, field visits & -34.11 & -44.52 & -56.74 \\
\hline \multirow{5}{*}{ 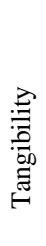 } & Well-equipped and maintained laboratories and classrooms & -38.47 & -58.67 & -20.46 \\
\hline & Library/Learning resources & -27.66 & -41.27 & -15.69 \\
\hline & Transport facilities & -51.50 & -34.45 & -6.14 \\
\hline & On Campus hostel and canteen facilities & -54.70 & -58.56 & -57.30 \\
\hline & Internet facilities and communication methods & -45.67 & -54.91 & -46.73 \\
\hline \multirow{5}{*}{ 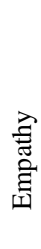 } & Counselling and mentoring process & -33.87 & -54.96 & -38.47 \\
\hline & Remedial/coaching classes for weak students & -33.91 & -62.19 & -32.31 \\
\hline & Willingness of faculty in solving student difficulties & -29.56 & -41.06 & -14.55 \\
\hline & Use of strategies such as teaching students in small batches & -20.04 & -38.47 & -15.19 \\
\hline & Training in aptitude and soft skills to help in placements & -43.29 & -49.47 & -28.13 \\
\hline \multirow{5}{*}{ 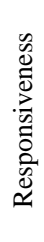 } & Timely addressing of student difficulties and problems & -32.80 & -62.36 & -34.73 \\
\hline & Awareness programs regarding opportunities for higher studies, education & -41.40 & -57.62 & -21.70 \\
\hline & Book bank and scholarship facilities for needy students & -40.04 & -18.15 & -32.76 \\
\hline & Promptness in addressing infrastructure and equipment failure & -57.89 & -41.45 & -33.94 \\
\hline & Effectiveness of Feedback mechanism and grievance redressal system & -44.34 & -44.60 & -56.44 \\
\hline
\end{tabular}

Table 4. Questionnaire statement coding

\begin{tabular}{|c|c|c|c|c|}
\hline Question/Statement & Coding & College 1 & College 2 & College 3 \\
\hline Timely completion of syllabus & A & -32.28 & -74.60 & -25.63 \\
\hline Provision of course material & $\mathrm{B}$ & -66.70 & -71.84 & -20.25 \\
\hline Remedial/coaching classes for weak students & $\mathrm{D}$ & -33.91 & -62.19 & -32.31 \\
\hline Timely addressing of student difficulties and problems & $\mathrm{E}$ & -32.80 & -62.36 & -34.73 \\
\hline
\end{tabular}

An approximation was done for each trial considering the level of factor for the college or group of colleges. If two colleges have the same level as required by a trial, then the average marks scored by the students of the two colleges were considered for analysis purposes. Later marks are added for all five factor levels and are averaged out for five trials. Now, 
for Trial 1 to keep all factors at a low level, the best response is scored by five students of college 2. For trial 2, factors A, B, and $\mathrm{C}$ are at low levels, and D and $\mathrm{E}$ are at high levels. Hence, the response is average for college 1 and the group of college 2 and college 3 .

Table 5. Factor level

\begin{tabular}{|c|c|c|c|c|}
\hline Factors & Question/Statement & College 1 & College 2 & College 3 \\
\hline A & Timely completion of syllabus & $\mathrm{H}$ & $\mathrm{L}$ & $\mathrm{H}$ \\
\hline $\mathrm{B}$ & Provision of course material & $\mathrm{L}$ & $\mathrm{L}$ & $\mathrm{H}$ \\
\hline $\mathrm{C}$ & Monitoring of teaching learning process & $\mathrm{H}$ & $\mathrm{L}$ & $\mathrm{H}$ \\
\hline $\mathrm{D}$ & Remedial/coaching classes for weak students & $\mathrm{H}$ & $\mathrm{L}$ & $\mathrm{H}$ \\
\hline $\mathrm{E}$ & Timely addressing of student difficulties and problems & $\mathrm{H}$ & $\mathrm{L}$ & $\mathrm{H}$ \\
\hline
\end{tabular}

Table 6. Experimental run for Machine Design and Total Marks

\begin{tabular}{|c|c|c|c|c|c|c|c|c|c|c|c|c|c|c|c|}
\hline \multirow{3}{*}{$\begin{array}{c}\text { Run } \\
1 \\
\end{array}$} & \multicolumn{5}{|c|}{ Factors } & \multirow{2}{*}{\multicolumn{5}{|c|}{ Marks scored in Machine Design }} & \multirow{2}{*}{\multicolumn{5}{|c|}{ Total Score }} \\
\hline & \multirow{2}{*}{$\frac{\mathrm{A}}{1}$} & \multirow{2}{*}{$\frac{\mathrm{B}}{1}$} & \multirow{2}{*}{$\frac{C}{1}$} & \multirow{2}{*}{$\frac{\mathrm{D}}{1}$} & \multirow{2}{*}{$\frac{E}{1}$} & & & & & & & & & & \\
\hline & & & & & & 72 & 72 & 66 & 61 & 57 & 533 & 519 & 467 & 459 & 454 \\
\hline 2 & 1 & 1 & 1 & 2 & 2 & 72 & 72 & 66 & 71 & 68 & 533 & 519 & 467 & 512 & 498 \\
\hline 3 & 1 & 2 & 2 & 1 & 1 & 72 & 72 & 66 & 61 & 57 & 533 & 519 & 467 & 459 & 454 \\
\hline 4 & 1 & 2 & 2 & 2 & 2 & 72 & 83 & 76 & 70 & 67 & 533 & 589 & 539 & 528 & 503 \\
\hline 5 & 2 & 1 & 2 & 1 & 2 & 71 & 68 & 68 & 67 & 65 & 512 & 498 & 488 & 485 & 485 \\
\hline 6 & 2 & 1 & 2 & 2 & 1 & 71 & 68 & 68 & 67 & 65 & 512 & 498 & 488 & 485 & 485 \\
\hline 7 & 2 & 2 & 1 & 1 & 2 & 72 & 83 & 76 & 70 & 67 & 533 & 589 & 539 & 528 & 503 \\
\hline 8 & 2 & 2 & 1 & 2 & 1 & 72 & 83 & 76 & 70 & 67 & 533 & 589 & 539 & 528 & 503 \\
\hline
\end{tabular}

\subsection{Results}

Marks scored by students in the Machine Design subject and the total score using L8 orthogonal array with five replicates are shown in Table 6. The variation in response is calculated using Signal to Ratio analysis for larger the better criteria. The effect of each factor on machine design and total score is calculated using S/N ratio and shown in Tables 7 and 8.

Table 7. Signal to Noise Ratio-Machine Design

\begin{tabular}{|c|c|c|c|c|c|}
\hline Levels & A & B & C & D & 36.58 \\
\hline 1 & 36.65 & 36.58 & 36.91 & 37.00 & 36.58 \\
\hline 2 & 36.94 & 37.01 & 36.68 & 0.42 & 0.42 \\
\hline Delta & 0.29 & 0.43 & 0.23 & 2.5 & 2.5 \\
\hline Rank & 4 & 1 & 5 & & 37.00 \\
\hline
\end{tabular}

Table 8. Signal to Noise Ratio-Total Marks

\begin{tabular}{|c|c|c|c|c|c|}
\hline Levels & A & B & C & D & 53.95 \\
\hline 1 & 54.00 & 53.86 & 54.23 & 54.27 & 53.95 \\
\hline 2 & 54.23 & 54.36 & 54.00 & 0.32 & 0.32 \\
\hline Delta & 0.22 & 0.50 & 4 & 2.5 & 2.5 \\
\hline
\end{tabular}

The effect of each factor on machine design and total score is shown in the form of delta statistics. Delta value is used to rank each factor in decreasing order of their influence on response. Among chosen factors, timely completion of syllabus (A), provision of course material (B), monitoring of teaching learning process (C), remedial/coaching classes for weak students (D) and timely addressing of student difficulties and problems (E), the maximum delta value is seen for provision of course material. This indicates that provision of course material is the predominant factor on machine design and the total score of students whereas remedial classes and timely addressing student difficulties are the second most influencing factors on machine design and total score. Timely completion of syllabus and monitoring teaching learning process are the next 
influencing factors on response. From Tables 7 and 8, it is clear that the optimum combinations of the factors to increase the score is $\mathrm{A}_{2} \mathrm{~B}_{2} \mathrm{C}_{1} \mathrm{D}_{2} \mathrm{E}_{2}$.

Optimum settings obtained from Signal to Ratio analysis are confirmed using the Grey Relation Analysis for larger the better characteristics. In Grey Relation Analysis, five replicates from the L8 orthogonal array are translated into a single value. The sum of five values is taken for analysis as shown in Table 9.

In grey relation analysis, response data for machine design and total score is normalized between zero and one. Subsequently, the delta value is calculated to obtain the grey relation coefficient. The computation of grey relation coefficient is shown in Table 10.

Table 9. Sum of Machine Design and Total Score

\begin{tabular}{|c|c|c|c|c|c|c|c|}
\hline \multirow{2}{*}{ Run } & \multicolumn{5}{|c|}{ Factors } & \multirow{2}{*}{$\begin{array}{c}\text { Machine } \\
\text { Design }\end{array}$} & $\begin{array}{c}\text { Total } \\
\text { Score }\end{array}$ \\
\cline { 2 - 6 } & $\mathrm{A}$ & $\mathrm{B}$ & $\mathrm{C}$ & $\mathrm{D}$ & $\mathrm{E}$ & 328 & 2432 \\
\hline 1 & 1 & 1 & 1 & 1 & 1 & 249 & 2529 \\
\hline 2 & 1 & 1 & 1 & 2 & 2 & 349 & 2432 \\
\hline 3 & 1 & 2 & 2 & 1 & 1 & 328 & 2692 \\
\hline 4 & 1 & 2 & 2 & 2 & 2 & 368 & 2468 \\
\hline 5 & 2 & 1 & 2 & 1 & 2 & 339 & 2468 \\
\hline 6 & 2 & 1 & 2 & 2 & 1 & 339 & 2692 \\
\hline 7 & 2 & 2 & 1 & 1 & 2 & 368 & 2692 \\
\hline 8 & 2 & 2 & 1 & 2 & 1 & 368 & \\
\hline
\end{tabular}

Table 10. Grey relation coefficient

\begin{tabular}{|c|c|c|c|c|c|c|c|}
\hline \multicolumn{4}{|c|}{ Machine Design } & \multicolumn{4}{|c|}{ Total Score } \\
\hline 328 & 0 & 1 & 0.5 & 2432 & 0 & 1 & 0.5 \\
\hline 349 & 0.525 & 0.475 & 0.677 & 2529 & 0.373 & 0.626 & 0.614 \\
\hline 368 & 1 & 0 & 1 & 2692 & 1 & 0 & 1 \\
\hline 339 & 0.275 & 0.725 & 0.579 & 2468 & 0.138 & 0.861 & 0.537 \\
\hline 339 & 0.275 & 0.725 & 0.579 & 2468 & 0.138 & 0.861 & 0.537 \\
\hline 368 & 1 & 0 & 1 & 2692 & 1 & 0 & 1 \\
\hline
\end{tabular}

The grey relation grade is then computed for each factor level by averaging the grey relation coefficient corresponding to the factor level in each run. The values of grey relation grades are as presented in Tables 11 and 12 for machine design and total score, indicating optimal factor levels.

Table 11. Grey Relation Grade for Machine Design

\begin{tabular}{|c|c|c|c|c|c|}
\hline Levels & A & B & C & D & 2.579 \\
\hline 1 & 2.677 & 2.337 & 3.177 & 3.257 & 3.257 \\
\hline 2 & 3.159 & 3.5 & 2.659 & E \\
\hline
\end{tabular}

Table 12. Grey Relation Grade for Total Score

\begin{tabular}{|c|c|c|c|c|c|}
\hline Levels & A & B & C & D & E \\
\hline 1 & 2.614 & 2.189 & 3.114 & 2.537 & 3.151 \\
\hline 2 & 3.074 & 3.5 & 2.574 & 3.151 \\
\hline
\end{tabular}


Grey relation analysis confirms the optimal level of factors as $\mathrm{A}_{2} \mathrm{~B}_{2} \mathrm{C}_{1} \mathrm{D}_{2} \mathrm{E}_{2}$. Hence, timely completion of syllabus (A), provision of course material (B), remedial/coaching classes for weak students (D), and timely addressing of student difficulties and problems (E) are to be kept at high levels, whereas monitoring of teaching learning process (C) can be kept at a low level to maximize the scores of students.

\subsection{Prediction of Machine Design and Total Score}

Once optimal levels are obtained, these levels are used to predict the corresponding values of response that characterize machine design and the total score of students. Predicted values are outputs of the Minitab software. A confirmation test is also conducted using optimal levels. Predicted and experimental values are tabulated in Table 13. Experimental results conducted at optimal setting shows results within the predicted value interval, which indicates that the model is statistically significant.

\begin{tabular}{|c|c|c|c|c|c|c|c|}
\hline \multirow{2}{*}{ Response } & \multicolumn{5}{|c|}{ Optimal factor setting } & \multirow{2}{*}{ Predicted } & \multirow{2}{*}{ Experimental } \\
\hline & $\mathrm{A}$ & $\mathrm{B}$ & $\mathrm{C}$ & $\mathrm{D}$ & $\mathrm{E}$ & & \\
\hline Machine Design Score & 2 & 2 & 1 & 2 & 2 & $\begin{array}{l}\text { Mean }=76.65 \\
\text { StDev }=5.08\end{array}$ & 73.6 \\
\hline Total Score & 2 & 2 & 1 & 2 & 2 & $\begin{array}{l}\text { Mean }=556.25 \\
\text { StDev }=27.17\end{array}$ & 538.4 \\
\hline
\end{tabular}

\section{Conclusions}

This paper is intended to improve the quality of higher education. The study's scope was limited to the technical education in Goa. The research was focused on mechanical third-year students across three engineering colleges in Goa. A face to face survey was conducted with a sample size of 180 students, sixty from each college. The SERVQUAL questionnaire form played an important role in collecting student perceptions and expectations towards services offered by various colleges. Soaring student dissatisfaction was found towards five services, which included timely completion of syllabus, provision of course material, monitoring of teaching learning process, remedial/coaching classes for weak students and timely addressing of student difficulties and problem. These services were considered for the quality improvement objective. Quality signal to noise ratio was estimated by considering mention services as a factor and machine design and total score as a response. Levels of factors were determined based on college operating levels. Based on our analysis, it was found that timely completion of syllabus, provision of course material, remedial/coaching classes for weak student, timely addressing of student difficulties and problems should be operated at high levels, and monitoring of teaching learning process should be operated at a low level to maximize response and thus improving quality. The same was confirmed using the grey relation analysis.

A prediction test and confirmation test were conducted to check the significance of statistical model. The confirmation experiment value was found to be within the predicted range of response, thus concluding that if colleges maintain levels of service as researched, the quality of education will improve. This methodology can be further extended to other services and colleges too.

\section{References}

1. A. Ardiente and J. M. V. Guiking, "Education and Its Contributions to the Economy," Journal of Economics and Economic Education Research, Vol. 16, No. 1, pp. 198-205, 2015

2. Y. A. Sheikh, "Higher Education in India: Challenges and Opportunities," Journal of Education and Practice, Vol. 8, No. 1, pp. 39-42, 2017

3. F. Buttle, "SERVQUAL: Review, Critique, Research Agenda," European Journal of Marketing, Vol. 30, No. 1, pp. 8-32, 1996

4. A. Shahin and M. Samea, "Developing the Models of Service Quality Gaps: A Critical Discussion," Business Management and Strategy, Vol. 1, No. 1, pp. 1-11, 2010

5. S. Athreya and Y. D, Venkatesh, "Application of Taguchi Method for Optimization of Process Parameters in Improving the Surface Roughness of Lathe Facing Operation," International Refereed Journal of Engineering and Science, Vol. 1, No. 3, pp. $13-19,2012$

6. N. Xydas, D. Tsi, V. Gurevich, M. Krichever, and I. Kao, "Dynamic Taguchi Methods and Parameter Design as Applied in Barcode Scanning and Scanners," Concurrent Engineering, Vol. 13, No. 1, pp. 69-80, 2005

7. R. Sallehuddin, S. M. H. Shamsuddin, S. Z. M Hashim, J. Skudai, and M. Roselina, "Grey Relational Analysis and Its Application on Multivariate Time Series," in Proceedings of IEEE International Conference on Intelligent Systems Design and Applications, Vol. 2, 2008 
8. A. N. Patil, N. G. P. Bhale, N. Raikar, and M. Prabhakaran, "Car Selection using Hybrid Fuzzy AHP and Grey Relation Analysis Approach," International Journal of Performability Engineering, Vol. 13, No. 5, pp. 569-576, 2017

9. S. Đonlagić and S. Fazlić, "Quality Assessment in Higher Education using the SERVQUAL Model," Management: Journal of Contemporary Management Issues, Vol. 20, No. 1, pp. 39-57, 2015

10. A. Mohanty and D. Dash, "Engineering Education in India: Preparation of Professional Engineering Educators," Journal of Human Resource and Sustainability Studies, Vol. 4, No.2, pp. 92-101, 2016

Amol Nayakappa Patil is an Assistant Professor in Department of Mechanical Engineering at Agnel Institute of Technology and Design, Assagao, Bardez, Goa, India. His areas of interest are Six Sigma, Quality Management, Lean Management and Supply Chain Management. 